Universitas Banten Jaya

\title{
SOURCE LANGUAGE VERSUS TARGET LANGUAGE TRANSLATION PROCEDURES
}

\author{
AKHMAD BAIHAQI \\ STKIP Syekh Manshur \\ Pandeglang, Indonesia \\ E-mail:mr.qrider@yahoo.com
}

\begin{abstract}
The objective of the research was to gain deep understanding of the translation procedures that occurred at the students' translation texts from English to Indonesian language in English Study Program of Teachers Training and Education College of Syekh Manshur in 2017. This research was conducted through qualitative content analysis. Data of the research were taken from the documentation of students' translation text; then, they were analyzed through the model of inductive category development. The result of the research showed that from total of 18 translation texts that had been analyzed, it was found there were 9 texts or $49.99 \%$ applied source language emphasized procedures, and 3 texts or $16.66 \%$ applied target language emphasized procedures. The research concludes that the existence of translation procedures in the translation process depends on either a problem in translating or the intention of naturalness.
\end{abstract}

Keywords: source language emphasized translation procedures, target language emphasized translation procedures 


\section{INTRODUCTION}

The study of translation does not only involve giving the equivalent meaning in the target language, rather it involves considering the values of the target language (TL) and the source language (SL) whether they are belonging to linguistic values, situational, or even cultural ones. As previously argued that translation does not merely comprise the understanding of both languages linguistically, but also relate to the understanding of situation and culture that attach of both languages (Baihaqi, 2017: 8). Therefore, in conducting one translation study, the translators may face whether linguistic, stylistic or even cultural problems when he tries to transfer meaning from the source language to target language.

Moreover, translation is a matter of skill, in line with its regard as science and art (Ordudari, 2009: 1). In this case, the translators need to practice their skills of translation that can be analyzed with a range of possibilities of methods, procedures, and even difficulties. Since the skill in translating can not be managed fully by the translators, it seems that the problem in translating is quite hard to be solved.

The common problems that are faced by the translator in translating the texts are usually come from the version of source language which can not be understood, or hard to be translated (Newmark, 1988: 33). It means, therefore, the correct translation does not only lay on the matter how the translator can transfer the meaning from source to target language, but also on how he can create his translation text in the way of naturalness.

When these situations occur, obviously, the translator skills in solving the problem or in creating the aspect of naturalness in translation are definitely urged. Of course, the ways that the writer means here are intended to the translators' skills in analyzing and applying the possibilities of translation procedures since they take the vital roles in translation study.

In contrast to the translation methods, translation procedures are used for sentences and its smaller units, such clauses, phrases, words, and morphemes (Baihaqi, 2017: 38). This means that the basic steps in 
analyzing and solving the problems in translation that deal with the smaller units of language are through the application of translation procedures. Since procedures deal with its smaller units of language, each theorist tries to propose these that may vary each other.

The first theory states that translation procedures can be classified into direct and oblique translation (Vinay and Derbelnet in Venuti, 2004: 128). Direct translation or transposing element of source language into target language includes borrowing, calque, and literal translation; on the other hand, oblique translation or corresponding element includes transposition, modulation, equivalence, and adaptation (Vinay and Derbelnet in Venuti, 2004: 129134). The term of borrowing refers to the way of words or phrases of source language that are directly used in target language. Then, calque is a special kind of borrowing when a language borrows an expression form of another. Literal refers to word for word translation. Next, transposition involves replacing one word class with another without changing the meaning of the message. Modulation itself refers to the variation of the form of message, and equivalence renders to the text in different stylistic and structural methods. Adaptation, the last, tries to result translation text in different situation and commonly used in literary texts.

In contrary to Vinay and Derbelnet, Newmark proposed the further procedures that are classified into transference or loan word, naturalization, cultural equivalent, functional equivalent, descriptive equivalent, synonymy, throughtranslation, shifts or transposition, modulation, recognized translation, translation label, compensation, componential analysis, reduction and expansion, paraphrase, couplets, notes, additions, and glosses (Newmark, 1988: 81-91). Naturalization refers to transference and adapts the source language word first to the normal pronunciation, then to the normal morphology. Cultural equivalent, then, refers to translation where a source language cultural word is translated by a target language cultural word. Functional equivalent applied to cultural words, and sometimes with a 
new specific term. Next, synonymy is used for a source language word where there is no clear one-to-one equivalent. Recognized translation and translation label are usually used for a new institutional term, while compensation occurs when loss of meaning in one part of a sentence is compensated in another part. Additionally, componential analysis is the splitting up of a lexical unit into its sense components.

From several theories proposed above, basically, translation procedures can be classified into two major categorizations. There are source language emphasized procedures and target language emphasized procedures (Baihaqi, 2017: 44). This dichotomy is actually based on the work of Vinay and Derbelnet of direct and oblique translation. Therefore, the source language emphasized procedures here include borrowing, calque, literal, and also naturalization. On the other hand, the other procedures emphasize to the target language.

According to the above explanation, it can be stated that each translation procedure has its characteristic and purpose. Thus, it is weird to such assumption that refer to what is the best translation procedures. Considering these, the previous research delivered that the translator might use a variety of procedures that differed in importance according to the contextual factors of both source and target texts (Zakhir, 2008: 1). Another research also proved that the application of psycholinguistics enabled the translators to determine structural and semantic characteristics of the original and target texts (Zasyekin, 2009: 5). Therefore, translation strategy includes its methods and procedures should not be regarded per se but should be contextualized as social systems that were loaded not only linguistic and cultural, but also social and politic (Tianmin, 2009: 1). Finally, due to the investigation for translation procedures are placed on the vital position in solving the problem in translation, the writer assumes that such discussion in the translation study is absolutely emerged. Of course, this discussion is absolutely required since the research itself is intended for understanding and enhancing 
translation study in educational area, especially in empowering the process of teaching and learning translation study in university level.

\section{METHOD}

Qualitative content analysis is used in this research. As a method in qualitative approach, as recenlty overviewed, content analysis provides new insight, increases a researcher's understanding of particular phenomena, or inform practical actions (Krippendorff, 2004: 18). In analyzing meaning and concepts, the method emphasizes in four points, such fitting the material into a model of communication, rules of analysis, categories in the center of analysis, and criteria of validity and reliability (Mayring, 2000: 3). The model here is conducted through inductive category development that intended to gain the accurate conclusion from systematic and systemic category of analysis.

Data of the research, furthermore, are taken from the documentation of students' translation texts which consisted of 18 texts. The texts are analyzed systematically through step by step formulation of inductive categories to gain a clear cut understanding towards the translation procedures that were used by the students in their translation texts.

\section{RESULT AND DISCUSSION}

The result of translation procedures analysis can be observed as the following explanations.

The first finding shows the use of translation procedure of calque. This procedure is used for translating SL phrase bed time into TL version waktu tidur. Calque, as previously viewed, tries to imitate structure or the way of source language expression into target language. If the version is translated literally, the result would be referred to out of context.

The next procedure is transference or loan word. This procedure was applied for translating the SL version of Valentine. Since there was no equivalent meaning for the version in the TL, as long as this version had been familiarly accepted to the target language readers; as a result, the version is directly borrowed into target language version phonologically and morphologically, i.e., Valentine.

The third procedure is basically 
quite different to the previous one, which is adaptation. The adaptation is found in interjection form of $S h h$ to Sst. This adaptation is intended to convert SL version into appropriate situation of expression of TL.

The forth procedure is transference. This procedure is applied for translating SL version microphone and speaker. These versions are directly transferred into TL. Although Indonesian Language have the equivalent meaning for those versions, i.e. pengeras suara for microphone and pelantam for speaker, the versions are directly transferred into target language words. These versions occurred since the TL readers already recognized the meaning of both SL versions.

The next procedure is adaptation. The adaptation here used to convert the name of Nasreddin into Nasruddin. This procedure tries to convert the culture of source language version in appropriate way and expression in culture of target language one.

The further procedure is transference or loan word. This procedure is applied for translating the
SL version orang utan. Since the version had been already availed in $\mathrm{TL}$, as a result, the version was directly borrowed into target language version in phonologically and morphologically.

The procedure in the next text is naturalization. This procedure tries to adapt the source language version in the normal pronunciation into normal morphology of the target language version. The naturalization here is for SL word remote into normal pronunciation and morphology of TL remot.

The next procedure is of calque. This procedure used to translate $\mathrm{SL}$ phrase the Day of the Dead into TL version Hari Orang Mati. As already viewed, calque tries to imitate the structure or the way of source language expression into target language one. If the version was translated word for word, of course the result would be referred to such of embarrassment and out of context.

The next translation procedure is naturalization. Naturalization is for SL version electromagnetic into $\mathrm{TL}$ normal pronunciation and morphology i.e., elektromagnetik. 
The next is expansion. Expansion found in SL clause the use of glove was not introduced until 1860 when the Marquis of Queensberry drew up the first set of rules'. This translated into 'pertandingan tinju pada masa tersebut tidak diperkenankan untuk menggunakan sarung tangan sampai pada tahun 1860, dan sampai akhirnya bangsawan Queensberry pertama kali membuat aturan'. The expansion here occurred when the translator tries to distort the nuances of meaning which does not exist in SL version. As a result, the translation version seemed to be out of the context and resulted a new version rather than the equivalent one.

Then, the next translation procedure is transference or loan word. This procedure is applied for translating the SL version such of Rampak Bedug, Ngadu Bedug, and Debus. Since the versions had been already availed in target language, as a result, the versions were directly borrowed into target language version phonologically and morphologically.

The last procedure is transference. The transference here used for SL version of Down syndrome. This version directly borrowed into TL version i.e., Down syndrome.

The result above can be summarized as the following table of cumulative frequency and percentage of translation procedures.

Table Cumulative Frequency and Percentage of Translation Procedures

\begin{tabular}{|c|c|c|c|}
\hline \multirow{2}{*}{ Num. } & \multirow{2}{*}{ Category } & \multicolumn{2}{|c|}{ Sum } \\
\hline & & $\mathbf{N}$ & $\%$ \\
\hline 1 & S. Emphasized Procedures & & \\
\hline & a. Transference & 5 & 27.77 \\
\hline & b Naturatzation & 2 & 11.1: \\
\hline & c. Calque & 2 & 11.1: \\
\hline & $n_{j}$ & 9 & 49.99 \\
\hline 2 & IL Emphasized Procadures & & \\
\hline & a. Adeptation & 2 & 11.1: \\
\hline & b Expansion & 1 & 5.55 \\
\hline & $n_{2}$ & 3 & 16.66 \\
\hline & $\boldsymbol{D} h$ & 12 & 66.65 \\
\hline
\end{tabular}

Based on the result above, it can be viewed that students commonly apply source language emphasized procedures rather than target language procedures. These results, of course, do not merely show students tendency in using source language emphasized procedures, but also possibly they are influenced by other factors.

Source language emphasized procedures put only any attention to the linguistic aspects (lexical, semantic, grammatical, and stylistic), however, the target language emphasized procedures attend to not only to the linguistic but also to the extra-linguistic aspects (situation, readers background, culture, etc). In 
the other words, if source language emphasized procedures investigate the equivalent meaning in one single aspect (linguistic), the target language emphasized procedures will investigate in both of linguistic and extra-linguistic aspects. As a result, the target language emphasized procedures need more attention from the translators rather than the source language procedures.

The source language emphasized procedures, moreover, focus the equivalence of translation only to the meaning itself. Consequently, these procedures assume that the correct translation will result from the equivalence on the meaning. On the other side, the target language emphasized procedures seek the equivalence to not only to the meaning, but also to the style. These procedures assume that the correct translation will result from the equivalence of both the meaning and style.

Besides, the source language emphasized procedures also assume that the literal translation is the matter of common process, even though this does not mean the allowance for mistranslation. If this situation occurred in the target language emphasized procedures, this will absolutely refer to the serious of mistranslation.

Since the students take roles as the beginners in translation study, the application of source language emphasized procedures in their translation tasks will be assumed as the common process considering their straightforward analysis and negotiating only to the meaning or message. This proves that the efforts for applying translation procedures are not only lay on the text and the context given, but also arrive from the translators' tendencies. The research also proves that the process of translation is not only refer to the matter of how the translators can transfer the meaning from source to target language correctly, but also reflected on how they produce translation texts naturally. Therefore, further studies are necessary in order to reveal better understanding towards these phenomena. 


\section{CONCLUSION}

Based on the discussion, it can be resolved that the students commonly apply the source language emphasized procedures on their translation texts due to its straightforward analysis and focusing only to the meaning. It proves that the efforts to apply the translation procedures are not only refer to the text and the context given, but also arrive from the translators' tendencies. This research also proves that the existence of translation procedures in one translation process depends on either a problem in translating or the intention of naturalness.

\section{REFERENCES}

Baihaqi, Akhmad, Penerjemahan dan Kesepadanan dalam Penerjemahan. Pandeglang: Staisman Press, 2017.

Krippendorff, Klaus. Content Analysis. California: Sage Publication, Inc., 2004.

Mayring, Philipp. "Qualitative Content Analysis." http://www.qualitativeresearch.net (Accessed in 3 July 2017).

Newmark, Peter. A Textbook of Translation. Hertfordshire: Prentice Hall Ltd., 1988.

Ordudari, Mahmoud. "Good Translation: Art, Craft, or Science?"

http://www.translationdirectory.co m (Accessed in 9 July 2017).

Tianmin, Jiang. "Translation in Context."

http://www.translationdirectory.co $\underline{m}$ (Accessed in 9 July 2017).

Venuti, Lawrence (Ed). The Translation Studies Reader: Second Edition. New York: Routledge, 2004.

Zakhir, Marouane. "Translation Procedures." 
Volume 1 No. 1, Agustus 2018

Universitas Banten Jaya

http://www.translatiosndirectory.c

om (Accessed in 7 July 2017).

Zasyekin, Serhiy. "Translation as a

Psycho-Semiotic Phenomenon."

http://www.translatiosndirectory.c

om (Accessed in 7 July 2017). 